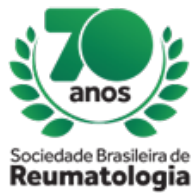

CENTRO DE EVENTOS DO CEARA O4 A 07 DE SETEMBRO

\title{
LATENT TUBERCULOSIS IN PATIENTS WITH RHEUMATOID ARTHRITIS: PROFILE OF PATIENTS SEEN AT A UNIVERSITY HOSPITAL OUTPATIENT CLINIC
}

Matheus Gomes Giacomini (FAMERP, São José do Rio Preto, SP, Brasil), Sarah Abati Curi Neaime (FAMERP, São José do Rio Preto, SP, Brasil), Pedro Henrique Marcondeli Correia (FAMERP, São José do Rio Preto, SP, Brasil), Laryssa Rocha Guimarães (FAMERP, São José do Rio Preto, SP, Brasil), Ricardo Acayaba Toledo (FAMERP, São José do Rio Preto, SP, Brasil), Roberto Acayaba Toledo (FAMERP, São José do Rio Preto, SP, Brasil), Rita de Cassia Menin (FAMERP, São José do Rio Preto, SP, Brasil)

\section{BACKGROUND}

Tuberculosis is a common chronic infection in our country, but a minority of individuals develop the disease in some of its clinical forms. The advent of anti-TNF was a major advance in the treatment of rheumatoid arthritis, but brought with it an increased risk of reactivation of latent tuberculosis.

The objective of this study is to establish an epidemiological profile of the patients treated at the university hospital rheumatoid arthritis outpatient clinic, in relation to the screening, prevalence and treatment of latent tuberculosis, mainly in individuals using biological DMARDs.

\section{MATERIALS AND METHODS}

Retrospective study, based on data collection of medical records of patients treated at the rheumatoid arthritis outpatient clinic, from $07 / 01 / 2017$ to $12 / 31 / 2017$.

\section{RESULTS}

In the period 303 patients with rheumatoid arthritis were treated, with a higher prevalence in females (85.4\%); the rheumatoid factor was present in $71.9 \%$ and the anti-CCP in $50.6 \%$ of the tested. A total of 112 patients were using biological DMARD (36.9\%). The latent tuberculosis screening was positive in $10.3 \%$ of the screened, and $91.6 \%$ completed the treatment with Isoniazid for 6 months. There were no cases of reactivation of tuberculosis in the treated patients with Isoniazid, as well as of tuberculosis in which the latent disease screening was negative.

The treatment with Isoniazid for 6 months was effective in our service, compatible with data from the literature, and it is also important to pay attention to the patients in whom the screening was negative. The most recent recommendation of the Ministry of Health (2017) guides the extension of treatment for latent tuberculosis to 270 doses of Isoniazid, but in our sample and in the literature studied there was no case of reactivation of tuberculosis in patients treated with 180 doses of the medication.

\section{CONCLUSION}

The screening of latent tuberculosis in patients with rheumatoid arthritis for the use of immunobiologicals resulted in a 6-month treatment of positive cases with good tolerance and without any case of active disease in the whole sample, minimizing the patient's exposure to possible side effects of isoniazid and likely providing better adherence. We emphasize that more studies, with more individuals, multicentric and prospective, should be performed to answer the questions still pending regarding latent tuberculosis and the use of biological DMARDs. 